\title{
Derin Öğrenme Yöntemleri ile Borsada Fiyat Tahmini
}

\author{
Gözde ŞIŞMANOĞLU, Furkan KOÇER, Mehmet Ali ÖNDE, Özgür Koray ŞAHİNGÖZ* \\ İstanbul Kültür Üniversitesi, Bilgisayar Mühendisliği Bölümü, İstanbul \\ (ORCID: 0000-0003-0284-4752) (ORCID: 0000-0002-0053-2459) \\ (ORCID: 0000-0001-9269-8554) (ORCID: 0000-0002-1588-8220)
}

\begin{abstract}
Öz
Son yıllarda, bilgisayarların donanımındaki teknolojik gelişmeler ve makine öğrenme tekniklerindeki gelişmeler nedeniyle, "Büyük Veri" ve "Paralel İşleme" kullanımı olmak üzere problem çözmek için iki artan yaklaşım vardır. Özellikle GPU'lar gibi çok çekirdekli bilgi işlem aygıtlarında paralel olarak gerçekleştirilebilen Derin Öğrenme algoritmalarının ortaya çıkmasıyla, bu yaklaşımlarla birçok gerçek dünya problemleri çözülebilmektedir. Derin öğrenme modelleri eğitildikleri veri ile sınıflandırma, regresyon analizi ve zaman serilerinde tahmin gibi uygulamalarda büyük başarılar göstermektedir. Bu modellerin finansal piyasadaki en aktif uygulama alanlarından biri özellikle borsada işlem gören hisse senetlerinin tahmini işlemleridir. Bu alanda amaç, pazardaki değişim süreci hakkındaki hisse senedinin önceki günlük verilerine bakarak kısa veya uzun vadeli gelecekteki değerini tahmin etmeye çalışmaktır. Bu çalışmada, LSTM, GRU ve BLSTM isimli 3 farklı derin öğrenme modeli kullanılarak bir hisse senedi tahmin sistemi geliştirilip, kullanılan modeller arasında karşılaştırmalı bir analiz yapıldı. Spekülatif hareketlerden uzak olması için veri seti olarak 1968'den 2018'e kadar olan New York Borsası'ndan hisse senedinin zaman serisi değerleri kullanıldı. Spesifik olarakta IBM hisse senedi ile test çalışmaları yapıldı. Deneysel sonuçlar, hisse senedine ait son 5 günlük işlem verilerinin girdi olarak kullanıldığı BLSTM modeliyle yapılan eğitimin \%63,54 lük bir yönsel doğruluk değerine ulaşıldığını göstermektedir.
\end{abstract}

Anahtar kelimeler: Büyük veri, Makine Öğrenmesi, Derin Öğrenme, LSTM, GRU, BLSTM, Fiyat Öngörme.

\section{Price Forecasting in Stock Exchange with Deep Learning Methods}

\begin{abstract}
In recent years, due to the technological advances in computer hardware and enhancements in machine learning techniques, there are two hot research areas in problem solving, the use of "Big Data" and "Parallel Processing". Many real-world problems can be solved with the use of different Deep Learning algorithms, which can be realized in parallel with multicore computing devices such as GPUs. Deep learning models show great success in applications such as classification of raw data, regression analysis and estimation in time series. One of the most active application areas of these models is "the financial market" which aims a good estimation of stock prices in the exchange market. In this paper, it is aimed to forecast the short or long term future value by looking at the previous log data of the stock on the process of change in the market. In this study, a price forecasting system was developed by using 3 different deep learning models named LSTM, GRU and BLSTM with a comparative analysis between them. The time series values of the stock were used from the New York Stock Exchange from 1968 to 2018 as a set of data to be free of speculative movements. Specifically, tests were conducted on IBM stock. Experimental results show that the directional accuracy of $63.54 \%$ was achieved with the BLSTM model where the last 5-day transaction data of the stock were used as input.
\end{abstract}

Keywords: Big Data, Machine Learning, Deep Learning, LSTM, GRU, BLSTM, Price forecasting.

\section{Giriş}

Modern topluluklarda finansal marketler sadece ekonomik değil sosyal organizasyonlarda da çok önemli bir yer almaktadır [1]. Para ve sermaye piyasalarındaki bireysel ve kurumsal yatırımcıların amacı,

\footnotetext{
*Sorumlu yazar: o.sahingoz@iku.edu.tr

Geliş Tarihi: 29.05.2019, Kabul Tarihi: 11.10.2019
} 
finansal piyasaların hareketlerini analiz etmek, piyasanın gidişine göre doğru bir tahmin yapmak ve ayırdıkları/yönettikleri bütçeyi bu yönde kullanmaktır. Gerek bu analizlerin yapılmasında gerekse yatırımların yönetilmesinde öncelikli olarak hedef alan Borsalar olarak göze çarpmaktadır. Borsalardaki hisse senetlerinin hareketleri farklı parametrelere bağlıdır. Bu parametrelerin uygun şekilde işlenmesi ve daha önceki veriler değerlendirilerek geliştirilen farklı modeller sayesinde gelecek dönemlerde hisse senetlerinin nasıl bir hareket izleyeceğinin öngörülmesi yatırımcılar için doğrudan para getirisi olan aktif bir araştırma alanıdır.

Yıllardan beri, sermaye piyasasındaki oyuncular borsa üzerindeki yatırımlarında karı arttırmak için farklı yöntem ve teknikler kullanmaya çalışmışlardır. Bu hareketlerin analiz edilmesi teknik ve temel analiz olmak üzere iki ana başlık altta toplanmıştır: Teknik Analiz ve Temel Analiz [2,3]. Teknik analiz, geçmiş fiyat hareketlerine dayanan gelecekte oluşabilecek fiyatların tahmini olarak açıklanabilir. $\mathrm{Bu}$ analiz türü, FOREX piyasası gibi değişikliğin yüksek olduğu piyasalarda kullanılan analiz yöntemidir ve genellikle kısa vadeli karar almak için kullanılmaktadır. Temel analiz yöntemi ise istatiksel verilere dayanan öngörmenin yanında, finansal, ekonomik, çevresel, politik ve diğer faktörlere de dayanarak beklenen fiyat hareketlerini önermektedir.

Teknik analiz kapsamında, artan işlem sayısının yanı sıra hisse senedi fiyatlarını tahmin etme girişimleri de uzun zamandır araştırma konusu olmuş ve çeşitli akademik araştırmalarda bazı yöntemler önerilmiştir. Ancak, sonuçlar hiçbir yöntemin tek başına istenen başarıya ulaşmadığını göstermektedir. Eski modeller biraz daha istatistik tabanlı veya benzerlik tabanlı yaklaşımlardan esinlenmekte ve fiyat hareketlerinin eski hareketlerle benzerliklerinden yararlanarak bir öngörüde bulunmaktadır. Genel olarak yatırımcılara tavsiyede bulunmak amaçlı olarak bir karar destek sistemi olarak geliştirilen bu sistemlerde, modern bir yaklaşım olarak, geçmiş verilerin uygun öğrenme mekanizmaları ile eğitilmesinin oldukça faydalı sonuçlar doğurduğu görülmektedir $[4,5]$.

Bilgisayar bilimi alanında, bu konuda, sistemin eğitimi için farklı öğrenme yaklaşımlarını kullanan, çoğunlukla geleneksel makine öğrenme yaklaşımının kullanımına odaklanan çok sayıda çalışma vardır. Bununla birlikte, son yıllarda bilgisayar donanımındaki hızlı gelişmeler ile güçlü bilgisayarların yaygın şekilde kullanılmaktadır. Bu sayede bilgisayarların, güncel bir çalışma alanı olan Büyük Veri (Big Data) işleme kabiliyeti de ciddi boyutta artmıştır [6, 18]. Geliştirilen modern öğrenme yaklaşımı olan Derin Öğrenme ile farklı gerçek dünyadaki uygulama alanlarını kullanmak için en cazip araştırma alanlarından biri olarak ortaya çıkmaktadır [7]. Daha önce geliştirilen standart makine ögrenmesi tabanlı sistemler, sahip oldukları yüksek başarım oranları sebebi ile birer birer farklı derin öğrenme algoritmaları kullanılarak yeniden geliştirilmektedir.

Bu çalışmanın amacı 3 farklı derin öğrenme algoritması kullanarak sahip olduğumuz uzun süreli hisse senetleri verileri ile derin öğrenme tabanlı bir Hisse Senedi tahmin sistemi geliştirmektir. Derin öğrenme modeli olarak kullanılan tekrarlayan sinir ağları (Recurrent Neural Network, RNN), birçok akademik çalışmada zaman serileri gibi sıralı verilerdeki gücünü kanıtlamıştır. Sistem iki farklı şekilde eğitilmiştir: 1 günlük veriye göre, son 5 günlük veriye göre. Bu eğitimde ilgili girdi verileri input olarak gönderilerek bir sonraki günkü hisse senedinin değeri tahmin edilmeye çalışılmıştır. Elde edilen yönsel doğruluk (directional accuracy) değerine göre hisse senedine al veya sat şeklinde komut verilmesi amaçlanmaktadır. Veri seti olarak yaklaşık 40 yıllık New York Borsas1 verileri baz alınarak sistem geliştirilmiştir. Çalı̧̧ma içerisinde farklı RNN mimarileri kullanarak (LSTM, GRU, BLSTM) performanslarını karşılaştırıp en iyi ulaşmış olduğumuz sonucu tespit ederek sonuç üzerinden kar hesaplaması yapılarak elde edilen sonuçlar paylaşılmıştır. Deneysel sonuçlar, önerilen sistemin tatmin edici sonuçlara ulaştı̆ıını göstermektedir.

Makalenin geri kalanı şu şekilde düzenlenmiştir. Bir sonraki bölümde, bazı arka plan bilgisi ve literatür araştırmaları sunulmaktadır. Bölüm 3, önerilen sistemin ilgili ayrıntıları aydınlatmakta olup ilgili parametreler ile yapılan deneysel sonuçlar Bölüm 4'te gösterilmektedir. Son olarak, bu çalışmadan elde edilen çıkarımlar özetlenerek makale sonuçlandırılmıştır.

\section{2. İlgili Çalışmalar}

\subsection{Literatürdeki çalışmalar}

Finansal zaman serilerinin tahmini, ekonomi dünyasında yatırımcılar için birincil öneme sahiptir. Son yıllarda, bu alanda yayınlanan yayınlarda büyük bir artış görüşmüştür. Korcak ve ark. 0'deki literatür 
taramasında önerdikleri modelde temel olarak A-Trader sistemi denilen sistemde bir satış ve satın alma stratejisi oluşturduğunu göstermektedir. A-Trader, Forex piyasasında alım satım kararları vermeyi amaçlamaktadır. Bu sistem yüksek frekanslı ticareti destekler. Klasik sinir ağları ve derin öğrenme modeli arasında karşılaştırma yapmak için tahminler incelenmiştir. MLP modeli, sigmoid aktivasyonu ve geri yayılım öğrenme algoritması işlevini kullanır. MLP modelinin sonucu tatmin edici değildi; bu nedenle daha karmaşık bir model geliştirilmeliydi. Sonuç olarak, A-Trader sisteminde Evrişimli Sinir Ağlarına (Convolutional Neural Network, CNN) dayanan ağ mimarileri kullanılmıştır. Diğer modellerle karşılaştırıldığında, CNN en iyi hata oranına sahip olarak, bu proje CNN'in bu model için MLP'den daha iyi olduğunu göstermiştir.

İnternet ve bilgisayar teknolojilerinin hızlı büyümesiyle, borsada işlem frekansının saniyeler içinde arttığı görülmüştür. Zhou ve ark. 0 yüksek frekanslı stok tahminini yapmak için eğitim için LSTM ve CNN'yi kullanan genel bir çerçeve önermiştir. Bu çalışma, tahmin hatası kaybını ve yön tahminini ve başarılı ters tahmin sonuçları üretmek için bu tahmin kayıplarını birleştirmede verimli ters eğitimin başarılı bir şekilde kullanılabileceğini göstermektedir.

Veri sayısı arttıkça, saniyede ürettiğimiz veriler hızla artıyor, bazı yazarlar Derin Sinirsel bir ağ sistemi uyguladılar 0 . Bu çalışmada veri kümeleri, bir tik bir (tick by tick) faaliyete karşllık gelen verilerinden oluşmaktadır. Bir işlem, bir teklif veya fiyat veya başka bir faaliyet olabilir. Günde yaklaşık 14 milyon veri noktası sistemlerinde kullanılmaktadır. Rapor, modellerinin performansını tahmin doğruluğunun yanı sıra tam gün işlem simülasyonları için öngörü hızına dayalı olarak da analiz etmektedir. Bu araştırmada, gerçek zamanlı olarak öngörülerde bulunurken her bir ürünün model ağırlıklarını paralel olarak güncellemeye devam etmek için yeterli hesaplama gücüne sahip olmanın önemi açıkça belirtilmiştir.

Arevalo ve ark. 0'de olduğu gibi birçok çalışma, mevcut çalışmaların yanı sıra, derin sinir ağlarına (Deep Neural Network, DNN) dayalı yüksek frekanslı bir strateji sunmaya odaklanmaktadır. DNN tahminleri, bir sonraki tahmini nihai kapanış fiyatının altında veya üstünde olup olmadığına bağlı olarak alma veya satma kararını veren bir mal alım satım stratejisi oluşturmak için kullanılmıştır. Mevcut en iyi DNN, \%66 doğruluk oranına sahiptir. Çalışmada geri yayılım algoritması kullanılmıştır. $\mathrm{Bu}$ araştırma, geri yayılım algoritmasının asıl sorunu olan gizli katmanlardan geçerken hatayı katlanarak seyreltme probleminin üstesinden gelmeyi amaçlamaktadır. Bu nedenle, bu proje DNN'lerin potansiyel bir çözüm sunabileceğini göstermiştir.

Bazı yazarlar ise 2 Boyutlu Evrişimli Sinir Ağları modelini kendi sistemlerini eğitmek için tercih etmişlerdir 0 . Bu kapsamda sadece hisse senedi fiyatı gibi teknik özelliklerin yanı sıra, bazı temel özelliklerde girdi olarak sisteme verilerek 2 boyutlu bir evrişim sürecinde sistem eğitilmiş ve çalıştırılmıştır. Sistem 2 sınıflı ve 3 -sınıflı olacak şekilde çalıştırılmıştır. 2 sınıflı yapıda sadece "AlSat" komutları üretilmiş, 3 sinıflı yapıda ise "Al-Tut-Sat" komutları üretilmiş ve sistem başarımları ona göre alınmıştır. Buna göre en iyi başarım değerlerinin 2 sınıflı "Al-Sat" sınıflandırması ile \%78,46 gibi olduğu ifade edilmektedir.

Borsa verilerinden asıl verimi elde etmek için kısa süreli tahmin yapmak özellikle dinamik kullanıcılar için önem arz etmektedir. Özellikle bir gün içerisindeki "Al-Sat" komutlarıyla kazanç sağlamak isteyen yatırımcılar farklı makine öğrenmesi algoritmaları kullanarak bu amaçlarına ulaşmaya çalışmışlardır $[15,16]$. Ancak bu tip sınıflandırma yapma işlemlerinde yeterli performans göstermekte zorluklarla karşılaşılması kaçınılmazdır. Karar verme sürecindeki özellik sayısını artırmak, doğru tahminde bulunma olasılığını artıracaktır. Ancak gerçek zamanlı verilerde bu dönüşümün yapılması işlem yoğunluğunu da ciddi boyutta artıracağı öngörülmektedir. Bu nedenle kendi çalışmamızda da daha somut sonuçların kullanılması açısından günlük verilerin kullanılması tercih edilmiştir.

\subsection{Makine öğrenmesi}

Makine öğrenmesi (Machine Learning) yapay zekânın bir alt kümesidir. Makine öğrenmesinin temel amac1, bazı durumlarda durumu insandan veya insandan daha iyi olarak tespit etmek, algilamak ve öğrenmektir. Makine öğreniminin kilit noktalarından biri insan etkileşimini en aza indirerek daha yüksek performans elde etmektir. Bu kararı verirken veri kalıplarını ve yapılarını analiz edebilen ve yorumlayabilen bilgisayar bilimi alanıdır. Makine öğrenmesi için verileri analiz etmek ve bu analizlerle sonuç çıarmak için bir algoritma gerekir. Günümüzde geliştirilmiş olan birçok algoritma 
bulunmaktadır. Bunlardan bazıları, ANN, SVM, DTR, KNN'dir. Herhangi bir makine öğrenme algoritması kullanılmadan önce eğitim verilerine en uygun modeli bulmak gerekmektedir.

\subsection{Derin öğrenme}

Derin Öğrenme, beynin yapısından ve Yapay Sinir Ağları denilen işlevlerinden ilham alan bir tür makine öğrenme algoritmasıdır. Biyolojik nöronlarda olduğu gibi, yapay nöronlar giriş sinyallerini alır, bu sinyaller toplanır ve işlenmiş ve çıkışlara iletilir.

Özellikle internetin gelişmesiyle birlikte dijital ortamda her saniye milyonlarca veri büyük boyutlarda üretiliyor ve depolanmaktadır. Şekil 1'den de görüleceği üzere, eğitim için kullanılan veri miktarı arttıkça, klasik makine öğrenme algoritmalarının büyük verilerle başa çıkmada performansı yeterli olmamıştır. Makine öğrenmesi algoritmaları gerek hızlı çalışması gerekse hızlı şekilde iyileşme sağlasa da günümüzde internetin yaygın kullanımı ile birlikte ulaşılabilen veri boyutu artmıştır. Hızlı sonuca ulaşmaktan ziyade ulaşılan sonucun performans değerinin daha iyi olması önem kazanmıştır. Derin öğrenme sistemleri ise bu büyük verileri etkili bir şekilde kullanarak verimli sonuçlar elde edebilmektedir. Diğer alanlardan farklı olarak, Derin öğrenme sınıflandırma özelliklerini ve görevlerini doğrudan veriden gerçekleştirmeyi öğrenir. Bazı modellerinde ilgili özelliklerin çıkarılmasına ihtiyaç duyulmadan doğrudan eğitim yapabilme olanağı bulunmaktadır. Derin öğrenme modelleri, insan düzeyinde öğrenmeyi başarmak ve hatta bu seviyeyi aşmak için farklı ve çok sayıda çok sinir ağı mimarisi kullanılarak eğitilebilir.

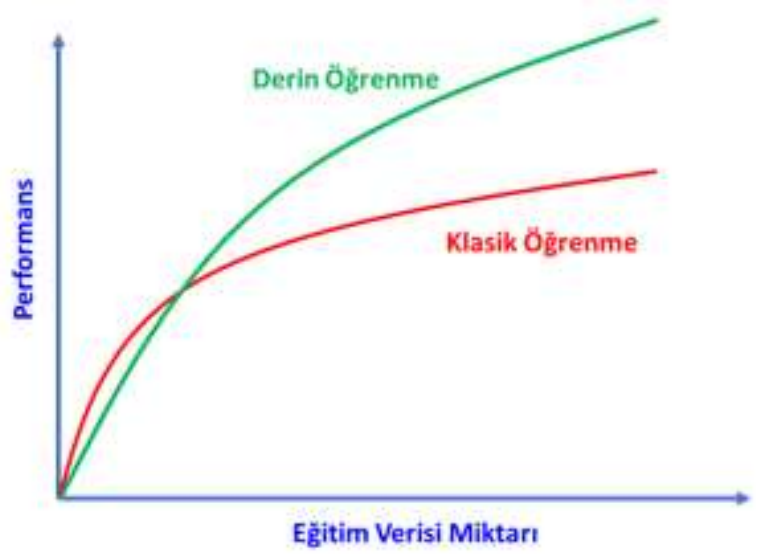

Şekil 1. Makine Öğrenmesi ve Derin Öğrenme Karşılaştırması

Derin ağlar, sistemin yüksek kaliteli GPU'lar kullanarak büyük verilerle eğitilmesine izin verir. Sonuç olarak, derin öğrenme için üst düzey donanıma ihtiyaç vardır. Bu yaklaşım, Hata! Başvuru kaynağı bulunamadı. 'da kullanıldığı gibi özellikle büyük veri analizi tipi problem çözme için en uygun seçenektir.

\section{3. Önerilen Sistem}

$\mathrm{Bu}$ çalışmada, önerilen yöntemin performansını IBM hisse senedi fiyatlarından toplanan verilere dayanarak değerlendiriyoruz. IBM'e ait geçmiş verilerin kullanılarak gelecekteki 300 gün için şirketin stok değerini öngören bir sistemin faklı derin öğrenme modelleri kullanılarak zaman serisine en uygun olan modeli tespit etmek amaçlanmıştır. Çalışmamızda Uzun-Kısa Vadeli Bellek (Long Short Term Memory-LSTM), Çift yönlü LSTM (Bidirectional LSTM-BLSTM) ve Kapılı Tekrarlayan Hücre (Gated Recurrent Unit-GRU) mimarileri kullanılmıştır. Geliştirilen sistemde kullanılan ana bileşenler ve veri seti bilgileri aşağıda detaylandırılmıştır.

\subsection{Veri seti}

Bu çalışmadaki veriler 2 Ocak 1968'den 9 Nisan 2018'e kadar olan NYSE, NASDAQ ve NYSE MKT'de işlem gören $\mathrm{ABD}$ merkezli hisse senetlerinin tamamı için günlük fiyat verilerinden oluşmaktadır. Veri 
girişi olarak, geliştirmiş olduğum 3 mimaride de son 5 günlük değerleri içeren 15 özellik kullanmış bulunmaktayız. Toplam 12.648 işlem günü bulunmaktadır. Elimizdeki son 300 veriyi daha sonra test aşamasında kullanabilmek için işlemedik. Bu çalışmada veri setinde 1968 ile 2018 arasında günlük hisse senedi fiyatları içeren örneklem büyüklüğü Büyük Veri olarak adlandırılacak kadar büyük sayılmamıştır.

Tablo 1. Veri Setindeki Sütunların Tanımı

\begin{tabular}{ll}
\hline SÜTUN ADI & TANIMI \\
\hline TARİH & İŞLEM GÜNÜ \\
\hline AÇILIŞ & AÇILIŞ FIY AT DEĞERİ \\
\hline KAPANIŞ & KAPANIŞ FIYYT DEĞERİ \\
\hline DÜŞÜK & GÜN İÇERİSINDEKİ EN DÜŞÜK FIYAT DEĞERİ \\
\hline YÜKSEK & GÜN İÇERİSINDEKİ EN YÜKSEK FIYAT DEĞERİ \\
\hline
\end{tabular}

$\mathrm{Bu}$ çalışmada sunulan verilerin değerlendirilmesi, bunun derin öğrenme algoritmalarıla yeterince doğru bir çözüm bulmak için yeterli olduğunu göstermektedir. Bu veri setinde, Tablo 1'de gösterildiği gibi veri setimizde, sistemimiz üzerinde çalışacak 5 özelliğe sahibiz. Ancak son güne ait hisse senedi verisi ile tahmin pek gerçekçi sonuç vermeyebileceği öngörülmektedir. Bu nedenle aynı verinin çoğullanarak, yani son birkaç günlük veriler yan yana getirilerek yeni bir girdi verisi oluşturmanın daha gerçekçi sonuçlar verebileceği öngörülerek veri seti 5 günlük veri setini tutacak şekilde yeniden oluşturulmuştur.

\subsection{Kullanılan derin öğrenme yaklaşımları}

Tekrarlayan sinir ağları (Recurrent Neural Network, RNN); cümleler, ses, müzik ve zaman serisi verileri gibi sıralı verileri modellemek için kullanılır. Ana fikir sıralı bilgi kullanmaktır. Geleneksel bir sinir ağındaki tüm girdi ve çıktıların birbirinden bağımsız olduğunu söyleyebiliriz. Tekrarlayıcı olarak adlandırılmalarının nedeni, bir dizinin her elemanı için aynı görevi tekrar tekrar gerçekleştirmeleridir. Bu yapıyı açıklamanın başka bir yolu, şu ana kadar neyin hesaplandığı hakkında veri toplayan "hafıza" taşımalarıdır. Şekil 2'de gösterilen diyagram tam bir ağa açılan RNN yapısını göstermektedir [17].

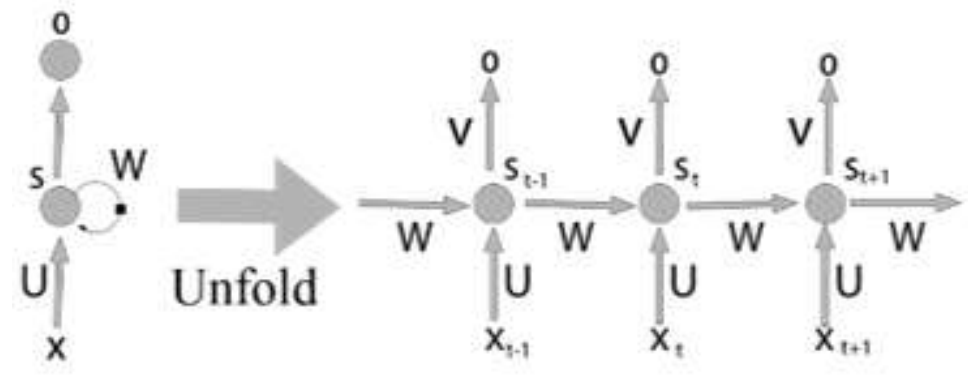

Şekil 2. RNN Şeması

LSTM yapıları, yok etme / sömürme (vanishing gradient) sorununun üstesinden gelmek için geliştirilmiştir. Bu problem tekrarlayan sinir ağı modellerini eğitmek için diğer modellerden daha zor bir süreçtir. Bir süre sonra, RNN'den geçen her adımda bilgi kaybedildiğinden, RNN ilk girişi "unutmaya" başlama problemi ile yüzleşir. Zaman serilerinin uzunluğuna bağlı olarak, bu problemin karmaşıklığı artış göstermektedir. Bu sorunlardan dolayı ağlarımızda bir çeşit "Uzun Süreli Bellek" gerekmektedir.

Karmaşık problemlerde, katman sayısı daha büyük olmalıdır. Bununla birlikte, bu tür modellerde istenmeyen sonuçlar elde edilebilir. Modelin ilk katmanlarını öğrenmek yavaştır ve sonraki katmanları öğrenmek kolaydır. Aksine, modelin ilk katmanlarının hızlı olduğu ve bir sonraki katmanların öğrenilmesinin yavaş olduğu durumlar da exploding gradient olarak adlandırılır. Bu gibi durumlar, modelin beklenen sonuçları yakalamamasına neden olur. LSTM katman yapıları bu gibi problemleri çözmek ve tekrarlayan yapay sinir ağı modellerini doğru şekilde oluşturmak için geliştirilmiştir. 
Nöronların kendi hafizasına sahip olduğu LSTM katmanlarında, geçmiş zaman verileri Şekil 3 'te gösterilen modelin gelişim sürecinde saklanır ve kullanılır. Eğitim sürecinde, bellekte saklanan verilerin şekillendirilmesi sağlanır. Bu şekilde, eski veriler bile yeni verilerle etkileşime girer ve daha etkili sonuçlar üreten bir ağ yapısı oluşturur [17].

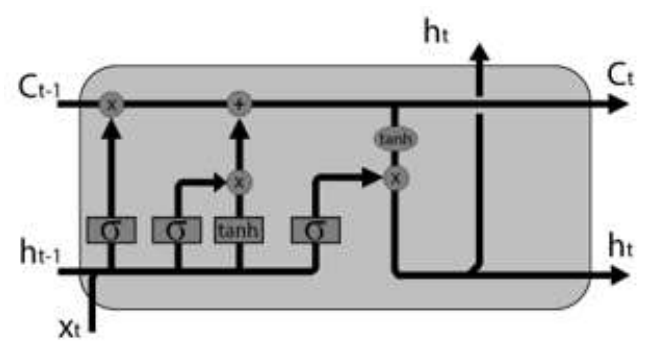

Şekil 3. LSTM Şeması.

BLSTM yap1 ve bağlantılar çift yönlü olarak Şekil 4'te gösterilmiştir. Birim zaman içinde ilerleyen, önceki gösterimlerden öğrenen ve gelecekteki gösterimlerle ileri geri öğrenmemize yardımc1 olan iki tür bağlantı vardır.

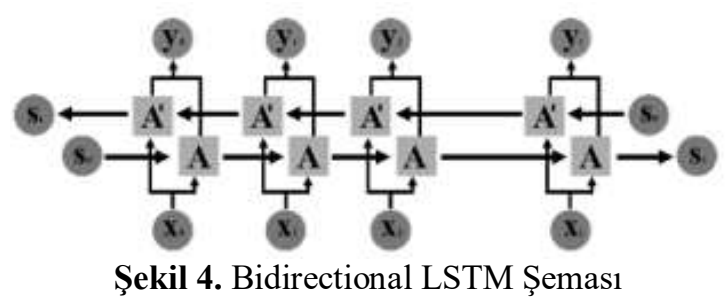

İleri yayılım iki farklı şekilde yapılır:

- Soldan sağa hareket ediyoruz, ilk adımdan başlıyoruz ve değerleri son zamana kadar hesaplıyoruz.

- Son adımdan başlayarak sağdan sola doğru hareket ederiz, ilk adıma ulaşana kadar değerleri hesaplarız.

GRU'da geçitli bir yineleme ünitesi, bir güncelleme portu ve bir sıfırlama kapısı kullanılır. Güncelleme geçidi, geçmişten gelen bilgilerin ne kadarının geçtiğine karar verirken sıfırlama geçidi, geçmişten gelen bilgilerin ne kadarının atıldığına karar verir.

Şekil 5'de Zt, güncelleme geçidi işlemini temsil eder, bu nedenle geçmişe hangi değerlerin geçileceğine karar vermek için bir sigmoid işlevi kullanılır. ht, önceki zaman adımından ve mevcut zaman adımından birleştirilen rt değerlerini birleştirdiğimiz sıfırlama geçidi işlemini temsil eder. $\mathrm{Bu}$, atmak istediğimiz değerleri önceki adımlardan üretilmektedir

\section{Bulgular ve Tartışma}

Önerilen model, aşağıdaki özelliklere sahip olan donanım ve yazılım içerisinde geliştirilmiştir. Donanım Bileşenleri: 9 MB Önbellek, Intel 8 çekirdekli, 8 GB RAM ve Ekran kartı ile $2.3 \mathrm{GHz}$ işlemci $4 \mathrm{~GB}$ GDDR5 nVIDIA ${ }^{\circledR}$ GeForce ${ }^{\circledR}$ GTX1050 128-Bit DX12. Programlama Dili: Python (v.3.5.2), makine öğrenim görevleri için olan kütüphanelerinden dolayı seçilmiştir.

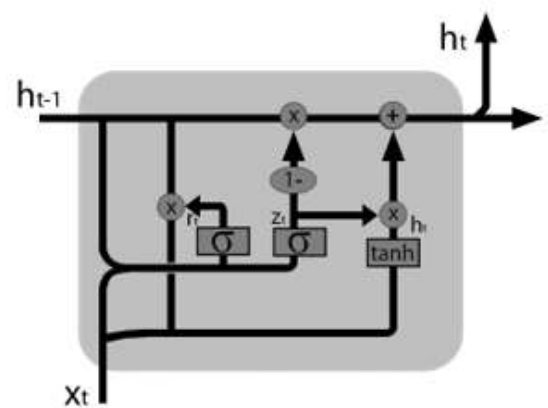

Şekil 5. GRU Şeması 
Tümleşik geliştirme ortamı: Geliştirme ortamı olarak PyCharm (3.6) tercih edilmiştir ve çalışma ortamı Anaconda modülleri ile genişletilmiştir. Makine Öğrenimi ve Destekleyici Kütüphaneler: Keras. Önerilen borsa tahmin modeli, Python'da Tensorflow arka planlı Keras kütüphanesi kullanılarak geliştirilmiştir. Öngörme performansını değerlendirmek istediğimiz hedef değer olarak "kapanış" değeri özelliği kullanılmıştır. Veriler günlük değişimlere odaklanarak işlenmiştir. Veri seti, eğitim verileri ve test verileri olmak üzere iki bölüme ayrılmıştır.

Zaman serisi tahmin performans ölçümleri, tahmin yapması beklenen tahmin modelinin kapasitesi hakkında temel bilgiler sağlamaktadır. Bu tip problemler standart bir sınıflandırma modeli gibi doğru ve yanlış şeklinde sınıflandırılamadığı için standart başarım (accuracy) değerinin haricinde kriterler kullanılması gerekmektedir. Çalışmada kullanılmış olan mimarilerin performanslarını analiz etmek için kullanılan hata ölçümleri modelleri olan Kök Ortalama Kare Hata- Root Mean Square Error (RMSE), Ortalama Kare Hata-Mean Squared Error (MSE), Ortalama Mutlak Hata -Mean Absolute Error (MAE) ve Yönsel Doğruluk-Directional Accuracy (DA) nin formülleri sirasılyla Denklem 1-4'te gösterilmiştir.

$$
\begin{gathered}
\text { RMSE }=\sqrt{\frac{1}{n} \sum_{i=0}^{n-1}\left(y_{i}-\hat{y}_{i}\right)^{2}} \\
\text { MSE }=\frac{1}{n} \sum_{i=0}^{n-1}\left(y_{i}-\hat{y}_{i}\right)^{2} \\
\text { MAE }=\frac{1}{n} \sum_{i=0}^{n-1}\left|y_{i}-\hat{y}_{i}\right| \\
\mathrm{DA}=\frac{(\mathrm{GP}+\mathrm{GN})}{(\mathrm{GP}+\mathrm{GN}+\mathrm{YP}+\mathrm{YN})}
\end{gathered}
$$

Modelimiz sadece "AL" ya da "SAT" kararı vereceği içi $2 * 2$ boyutunda bir matris oluşturulmuştur. Denklem 4'te kullanılmış olan değerler Tablo 2'de gösterilen matriste hesaplanmış olan Gerçek Pozitifler (GP), Gerçek Negatifler (GN), Yanlış Pozitifler (YP) ve Yanlış Negatifler (YN) değerlerdir.

Tablo 2. Karmaşıklık Matrisi (Confusion Matrix).

\begin{tabular}{lcc}
\hline & Negatif Tahmin & Pozitif Tahmin \\
\hline Gerçek Negatif & GN & YP \\
\hline Gerçek Pozitif & YN & GP \\
\hline
\end{tabular}

3 faklı derin öğrenme modeli önerilen sistem üzerinde test edilmiştir. Kullanılan modeller ve parametreler Tablo 3'te gösterilmektedir. 
Tablo 3. Kullanılan Modeller ve Parametreler

\begin{tabular}{|c|c|}
\hline $\begin{array}{l}\text { Derin Öğrenme } \\
\text { modeli }\end{array}$ & Kullanılan Parametreler \\
\hline LSTM & $\begin{array}{l}\text { Tek Katman } \\
128 \text { neurons, activation=sigmoid, optimizer=rmsprop, dropout }=0.2\end{array}$ \\
\hline GRU & $\begin{array}{l}\text { Toplam Ü̧̧ Katman } \\
\text { Birinci Katman }(64 \text { neurons, activation=tanh, optimizer=adam, dropout=0.2) } \\
\text { İkinci Katman }(16 \text { neurons, activation=tanh, optimizer=adam, dropout }=0.2) \\
\text { Üçüncü Katman ( } 64 \text { neurons, activation=tanh, optimizer=adam, dropout= } 0.2)\end{array}$ \\
\hline BLSTM & $\begin{array}{l}\text { Toplam Üç Katman } \\
\text { Birinci Katman }(64 \text { neurons, activation=tanh, optimizer }=\text { adam, dropout }=0.2) \\
\text { İkinci Katman }(16 \text { neurons, activation=tanh, optimizer }=\text { adam, dropout }=0.2) \\
\text { Üçüncü Katman ( } 64 \text { neurons, activation=tanh, optimizer=adam, dropout }=0.2)\end{array}$ \\
\hline
\end{tabular}

5 günlük veri girişine göre LSTM mimarisi 100 iterasyon eğitilmiş olup elde edilen gerçek fiyat ve tahmin grafiği Şekil 6'da, kullanılan 300 günlük test verisine göre elde edilen sonuçlarla sunulmaktadır. Burada gösterilen siyah grafik takip edilen hisse senedinin gerçek değerini, kırmızı grafik ise yapılan tahmin değerini göstermektedir. Önemli olan kırmız veya siyah grafiğin yukarıda veya aşağıda olmasından ziyade, o gün içerisinde verilen "al" veya "sat" kararıdır. İlgili kararın doğru verilip verilmediğine göre "yönsel doğruluk" değerine ulaşılmaktadır.

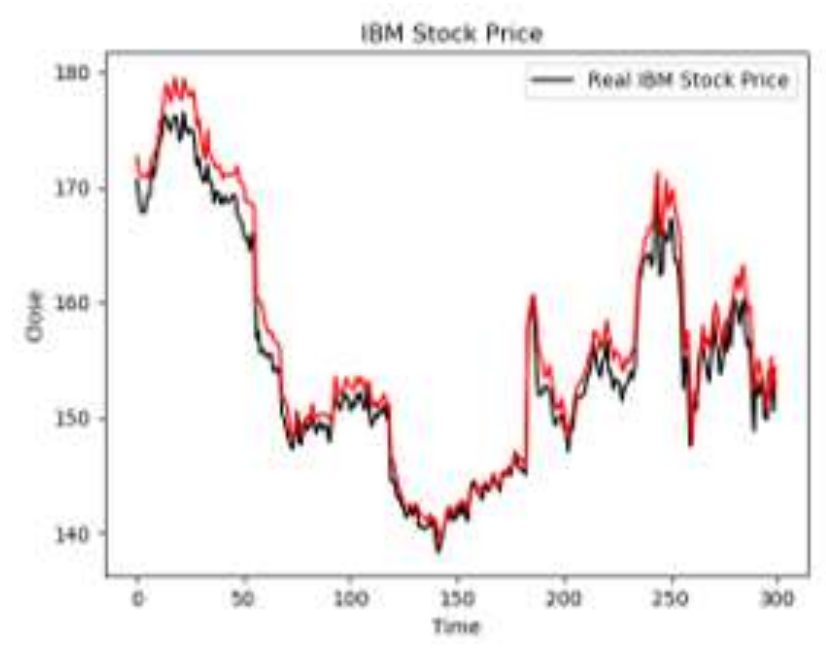

Şekil 6. LSTM Test verileri.

Bu verilere göre elde edilen karmaşıklık matrisi değerleri Tablo 4'te sunulmakta olup bu değerlerden \% 57,52 lik bir başarım oranına ulaşıldığg görülmektedir.

Tablo 4. LSTM Karmaşıklık Matrisi

\begin{tabular}{|l|c|c|}
\hline & Negatif Tahmin & Pozitif Tahmin \\
\hline Gerçek Negatif & 23 & 4 \\
\hline Gerçek Pozitif & 123 & 149 \\
\hline
\end{tabular}

5 günlük veri girişine göre GRU mimarisi 100 iterasyon eğitilmiş olup elde edilen gerçek fiyat ve tahmin grafiği Şekil 7'de, kullanılan 300 günlük test verisine göre elde edilen sonuçlarla sunulmaktadir. 


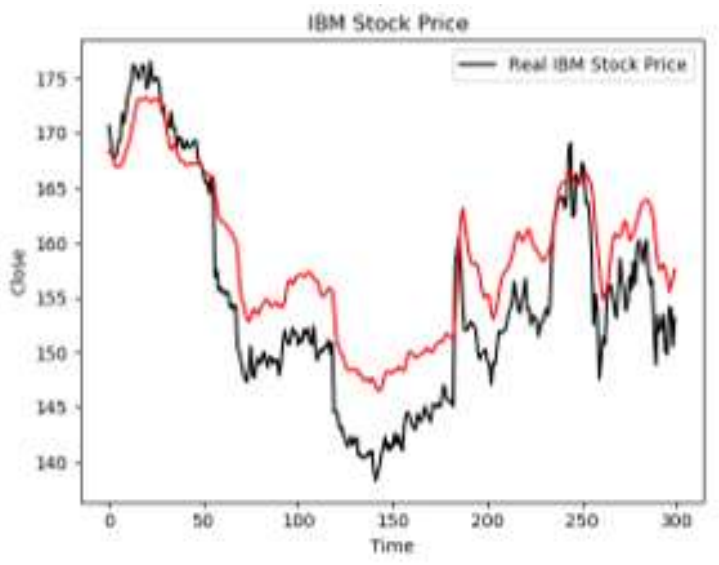

Şekil 7. GRU Test verileri.

$\mathrm{Bu}$ verilere göre elde edilen karmaşıklık matris değerleri Tablo 4'te sunulmakta olup bu değerlerden \% 52,17 lik bir başarım oranına ulaşıldığı görülmektedir.

Tablo 4 GRU Karmaşıklık Matrisi

\begin{tabular}{|l|l|l|}
\hline & Negatif Tahmin & Pozitif Tahmin \\
\hline Gerçek Negatif & 31 & 28 \\
\hline Gerçek Pozitif & 115 & 125 \\
\hline
\end{tabular}

5 günlük veri girişine göre BLSTM mimarisi 100 iterasyon eğitilmiş olup elde edilen gerçek fiyat ve tahmin grafiği Şekil 8'de, kullanılan 300 günlük test verisine göre elde edilen sonuçlarla sunulmaktadir.

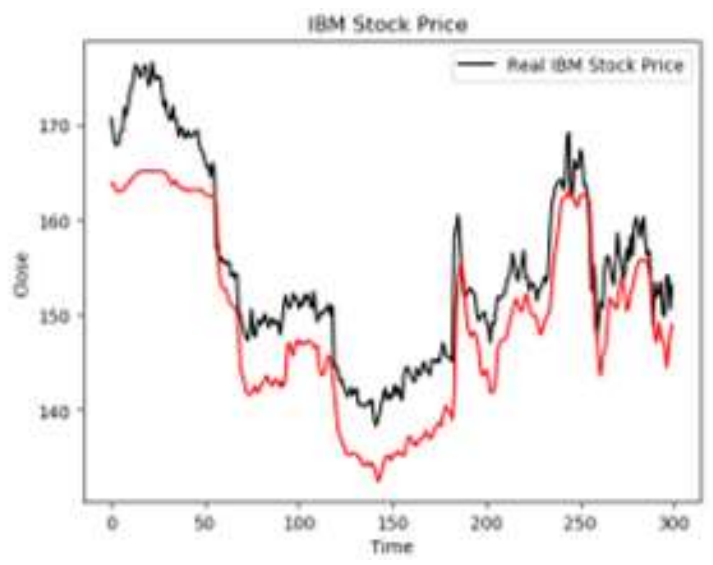

Şekil 8. BLSTM Test verileri.

Bu verilere göre elde edilen karmaşıklık matris değerleri Tablo 6'da sunulmakta olup bu değerlerden \% 63,54 lik bir başarım oranına ulaşıldığı görülmektedir.

Tablo 6. BLSTM Karmaşıklık Matrisi

\begin{tabular}{|l|c|c|}
\hline & Negatif Tahmin & Pozitif Tahmin \\
\hline Gerçek Negatif & 73 & 36 \\
\hline Gerçek Pozitif & 73 & 117 \\
\hline
\end{tabular}

Bir test senaryosu olarak, öncelikle sistemimizi farklı mimariler ile eğittik ve gerçek stok verilerini öngörülen değerle karşılaştırarak hata ölçüm formüllerimizi kullanarak tahmin doğruluğunu kontrol ettik ve kullanmış olduğumuz mimarileri karşılaştırdık.

Son olarak, yapılmış olan testlerin bazı performans sonuçları Tablo 7'de kısaca gösterilmiştir. $\mathrm{Bu}$ tablodan görülebileceği gibi ulaşılan değerler tüm mimariler için kabul edilebilir ve önerilen modeller bazı gerçek dünya durumlarında kullanılabilir. Ancak bizim için yön tahmin etme konusunda 
en önemli olan DA'nın en iyi sonuç verdiği mimarimiz olan BLSTM bizi en yüksek kâr marjına götürebileceği aşikardır.

Tablo 7. Performans Değerleri (5 günlük girdi için)

\begin{tabular}{cccccc}
\hline MimaRi & $\begin{array}{c}\text { EĞíím } \\
\text { Süresí(DK) }\end{array}$ & RMSE & MSE & MAE & DA(\%) \\
\hline LSTM & 60 & 0,01 & 0,0001 & 0,004 & 57,52 \\
\hline GRU & 142 & 0,03 & 0,0006 & 0,015 & 52,17 \\
\hline BLSTM & 195 & 0,01 & 0,0001 & 0,010 & $\mathbf{6 3 , 5 4}$ \\
\hline
\end{tabular}

Bundan dolayı, bir gerçek hayat örneği olarak BLSTM modelimiz tarafından verilen alım satım kararları sonucunda ne kadar kar elde ettiğimizi belirlemek için kullanıcının işlem yapmak için $\$ 100.000$ 'lık bir bütçe ayırmış olması varsayılmıştır. Eğer tahmin edilen karar ve gerçekte verilmesi gereken karar aynı ise kar elde edilecek, eğer tahmin ve gerçek karar aynı olmazsa zarar elde edilmiş olarak hesaplanacaktır. Kar ve zarar hesabı günlük olarak alınan kararlara göre, kullanıcının tahmin edilen değer anında işlem yapmış ve bir sonraki tahmine geçtiğinde işlemi kapatmış olması şeklinde hesaplanacaktır. Her tahmin anında yeni bir işlem başlatmış olması ve bütün bakiye ile işlem yapılması beklenecektir.

Yukarıda bahsedilen deneysel testler 5 günlük verinin analizi üzerinden yapılmıştır. Ancak daha kısa süreli (örneğin 1 günlük) veri üzerinden eğitilen sistemin nasıl sonuç verdiği de ölçülmek istenmiştir. Bu değerlendirme sonucunda ulaşılan performans değerleri Tablo 8'de sunulmaktadır.

Tablo 8. Performans Değerleri (1 günlük girdi için)

\begin{tabular}{cccccc}
\hline MiMARi & $\begin{array}{c}\text { EĞíTiM } \\
\text { Süresi (DK) }\end{array}$ & RMSE & MSE & MAE & DA(\%) \\
\hline LSTM & 32 & 0.01 & 0.00007 & 0,004 & $\mathbf{6 1 , 3 2}$ \\
\hline GRU & 50 & 0.02 & 0.0004 & 0,013 & 55,78 \\
\hline BLSTM & 78 & 0.02 & 0.0002 & 0,009 & 54,70 \\
\hline
\end{tabular}

Elde edilen sonuçlara göre 5 günlük girdi ile eğitilen sistemin ortalama olarak daha iyi tahmin performansı olduğu görülmektedir. Rakamsal bir karşılaştırma olması açısından BLSTM modelinde 1 günlük veri girişi yapılarak çalıştırılmış ve Tablo 9'de bulunan sonuçlar elde edilmiştir. Bu örnek çalıştırım sonucuna göre 10 gün sonunda yalnızca \%2,86 kar sağlandığı görülmektedir.

Karşılaştırma olması açısından aynı tarih aralığı içerisinde BLSTM modeli 5 günlük veri girişi yapılarak çalıştırılmış ve Tablo 10'de bulunan sonuçlar elde edilmiştir. Bu örnek çalıştırım sonucuna göre 10 gün sonunda yalnızca toplamda $\% 13,47$ kar getirisi olmuştur.

Tablo 9. 1 Günlük veri girişi ile 10 günlük kazanç tablosu.

\begin{tabular}{ccccc}
\hline $\begin{array}{c}\text { GERÇEK } \\
\text { DEĞER }\end{array}$ & $\begin{array}{c}\text { ÖNGÖRÜLEN } \\
\text { DEĞER }\end{array}$ & $\begin{array}{c}\text { ÖNGÖRÜLEN } \\
\text { işLEM }\end{array}$ & $\begin{array}{c}\text { ASIL } \\
\text { İşLEM }\end{array}$ & BAKIYE \\
\hline 148,89 & 161,537 & $\mathrm{AL}$ & $\mathrm{AL}$ & $100.000,00$ \\
\hline 153,37 & 161,937 & $\mathrm{AL}$ & $\mathrm{AL}$ & $103.008,93$ \\
\hline 151,91 & 163,717 & $\mathrm{AL}$ & $\mathrm{SAT}$ & $102.028,34$ \\
\hline 152,52 & 162,518 & $\mathrm{AL}$ & $\mathrm{AL}$ & $102.438,04$ \\
\hline 153,43 & 162,975 & $\mathrm{AL}$ & $\mathrm{AL}$ & $103.049,23$ \\
\hline 150,07 & 162,731 & $\mathrm{AL}$ & $\mathrm{SAT}$ & $100.792,53$ \\
\hline 149,85 & 159,242 & $\mathrm{AL}$ & $\mathrm{SAT}$ & $100.644,77$ \\
\hline 154,12 & 160,832 & $\mathrm{AL}$ & $\mathrm{AL}$ & $103.512,66$ \\
\hline 154,03 & 163,840 & $\mathrm{AL}$ & $\mathrm{SAT}$ & $103.452,21$ \\
\hline 150,57 & 163,155 & $\mathrm{AL}$ & $\mathrm{SAT}$ & $101.128,35$ \\
\hline 153,15 & 162,999 & $\mathrm{AL}$ & $\mathrm{AL}$ & $102.861,17$ \\
\hline
\end{tabular}

Elde edilen değerler incelendiğinde Yönsel doğruluk değerlerinin farklı makine öğrenmesi uygulamalarında karşılaşıldığı gibi \% 80-90'larda olmadığı görülmektedir. Tasarlanan sistem bir karar destek sistemi olarak geliştirilmiş olup karar vericiye parametrik destek sağlaması amaçlanmaktadır. \%55'lik başarımı bile göz önüne aldığımızda bu verinin toplam (cumulative) hesaplamada ciddi kar ortaya koyacağı görülmektedir. Zaten para piyasası gibi mali konular üzerinde geliștirilecek bir uygulamada çok fazla girdi olduğu, sadece teknik analiz değil temel analiz faktörlerinin de etkisinin 
gözönüne alınması gerekmektedir. Bu anlamda geliştirilen sistemin başarılı sonuçlar verdiği, deneysel çalışmalar ile ortaya konmuştur.

Tablo 10. 5 Günlük Veri Giriși ile 10 günlük kazanç tablosu.

\begin{tabular}{ccccc}
\hline $\begin{array}{c}\text { GERČEK } \\
\text { DEĞER }\end{array}$ & $\begin{array}{c}\text { ÖNGÖRÜLEN } \\
\text { DEĞER }\end{array}$ & $\begin{array}{c}\text { ÖNGÖRÜLEN } \\
\text { İşLEM }\end{array}$ & $\begin{array}{c}\text { ASIL } \\
\text { İşLEM }\end{array}$ & BAKIYE \\
\hline 148,89 & 152,107 & $\mathrm{AL}$ & $\mathrm{AL}$ & $100.000,00$ \\
\hline 153,37 & 152,345 & $\mathrm{AL}$ & $\mathrm{AL}$ & $103.008,93$ \\
\hline 151,91 & 152,999 & $\mathrm{SAT}$ & $\mathrm{SAT}$ & $103.998,95$ \\
\hline 152,52 & 152,603 & $\mathrm{AL}$ & $\mathrm{AL}$ & $104.416,56$ \\
\hline 153,43 & 151,925 & $\mathrm{SAT}$ & $\mathrm{AL}$ & $103.797,26$ \\
\hline 150,07 & 151,606 & $\mathrm{SAT}$ & $\mathrm{SAT}$ & $106.121,23$ \\
\hline 149,85 & 151,126 & $\mathrm{AL}$ & $\mathrm{SAT}$ & $105.965,66$ \\
\hline 154,12 & 151,0482 & $\mathrm{AL}$ & $\mathrm{AL}$ & $108.985,17$ \\
\hline 154,03 & 153,1418 & $\mathrm{SAT}$ & $\mathrm{SAT}$ & $109.048,85$ \\
\hline 150,57 & 152,135 & $\mathrm{SAT}$ & $\mathrm{SAT}$ & $111.554,72$ \\
\hline 153,15 & 151,951 & $\mathrm{AL}$ & $\mathrm{AL}$ & $113.466,20$ \\
\hline
\end{tabular}

\section{Sonuç ve Öneriler}

Borsalarda doğru tahminler yapmak, finansal zaman serilerinin lineer olmayışı nedeniyle karmaşık bir işlemdir. Bu alandaki bazı araştırmacılar, hisse senedi fiyatlarının rastgele bir yürüyüş şeklinde davrandığını söylemektedirler. Ancak, teknik analistler, bazı güncel değerler dikkate alınarak gelecekteki fiyatların bir şekilde tahmin edilebileceği konusunda 1srar etmektedirler. Bu yazıda, derin öğrenme yaklaşımlarından olan LSTM, GRU ve BLSTM modelleri ile gelecekteki değerleri tahmin etmek için 2 Ocak 1968'den 9 Nisan 2018'e kadar değişen geniş çaplı bir borsa NYSE, NASDAQ ve NYSE MKT'ye uygulanmaktadır. Önerilen mimarilerinin kullanılmasıyla, piyasanın bazı gizli dinamikleri yakalanabilir ve etkili tahminler mümkün olabileceği görülmüştür. Önerilen modeller arasından 5 günlük girdiler ile eğitilen BLSTM \%63,54'lük yönsel doğruluk oranı ve 0,01'lik RMSE değeri ile en iyi sonucu vermiş, 10 günün sonunda $\% 13,47$ kar getirdiği tespit edilmiştir.

Gelecekteki çalışma olarak, daha doğru tahminler yapmak için bazı yeni özellikleri göz önünde bulundurmayı hedefledik. Ek olarak, sistemin verimliliğini artırmak için bazı optimizasyon algoritmaları kullanılarak bazı parametre değerleri ayarlanabilir mimarilerinin kullanılmasıyla, piyasanın bazı gizli dinamikleri yakalanabilir ve etkili tahminler mümkün olabilir. Sistem performansının daha da artırılabilmesi için daha büyük verilerin kullanılması fayda sağlayacaktır. Büyük verilerin işlenmesi ve eğitim süresinin kısaltılması için paralel platformda sistemi çalıştırmak için sistem 0 'de belirtildiği gibi GPU tabanlı hesaplama ortamlarına aktarılabilir.

\section{Yazarların Katkısı}

G. ŞIŞMANOĞLU, F. KOÇER ve M.A. ÖNDE çalışmanın içerik tasarımına, verilerin toplanması, sistemin geliştirilmesine, test sonuçlarının analiz ve yorumuna, makalenin hazırlanmasına katkı sunmuştur. Ö.K. ŞAHINGÖZ çalışmanın içerik tasarımına, kullanılacak algoritmaların belirlenmesine, makalenin düzeltilmesine ve makalenin son haline gelmesine katkı sunmuştur.

\section{Çıkar Çatışması Beyanı}

Yazarlar arasında herhangi bir çıkar çatışması bulunmamaktadır.

\section{Araştırma ve Yayın Etiği Beyanı}

Yapılan çalışmada, araştırma ve yayın etiğine uyulmuştur. 


\section{Kaynaklar}

[1] Cavalcante R.C., Brasileiro R.C., Souza V.L., Nobrega J.P., Oliveira A.L. 2016. Computational intelligence and financial markets: A survey and future directions. Expert Systems with Applications, 55: 194-211.

[2] Namdari A., Li Z.S. 2018. Integrating Fundamental and Technical Analysis of Stock Market through Multi-layer Perceptron. 2018 IEEE Technology and Engineering Management Conference (TEMSCON), Evanston, IL, 1-6. doi: 10.1109/TEMSCON.2018.8488440.

[3] Beyaz E., Tekiner F., Zeng X., Keane J. 2018. Comparing Technical and Fundamental Indicators in Stock Price Forecasting. 2018 IEEE 20th International Conference on High Performance Computing and Communications; IEEE 16th International Conference on Smart City; IEEE 4th International Conference on Data Science and Systems (HPCC/SmartCity/DSS), Exeter, United Kingdom, 1607-1613.

[4] Chou J., Nguyen T. 2018. Forward Forecast of Stock Price Using Sliding-Window MetaheuristicOptimized Machine-Learning Regression. in: IEEE Transactions on Industrial Informatics, 14 (7): 3132-3142.

[5] Lien Minh D., Sadeghi-Niaraki A., Huy H.D., Min K., Moon H. 2018. Deep Learning Approach for Short-Term Stock Trends Prediction Based on Two-Stream Gated Recurrent Unit Network. in: IEEE Access, 6: 55392-55404.

[6] Trelewicz J.Q. 2017. Big Data and Big Money: The Role of Data in the Financial Sector. in: IT Professional, 19 (3): 8-10.

[7] Mohammadi M., Al-Fuqaha A., Sorour S., Guizani M. 2018. Deep Learning for IoT Big Data and Streaming Analytics: A Survey. in: IEEE Communications Surveys \& Tutorials, 20 (4): 2923 2960.

[8] Korczak J., Hernes M. 2017. Deep Learning for Financial Time Series Forecasting in A-Trader System. Proceedings of the 2017 Federated Conference on Computer Science and Information Systems.

[9] Arévalo A., Niño J., Hernández G., Sandoval J. 2016. High-Frequency Trading Strategy Based on Deep Neural Networks. Intelligent Computing Methodologies Lecture Notes in Computer Science, 424-436.

[10] Zhou X., Pan Z., Hu G., Tang S., Zhao C. 2018. Stock Market Prediction on High-Frequency Data Using Generative Adversarial Nets. Mathematical Problems in Engineering, 2018: 1-11.

[11] Ganesh P., Rakheja P. 2018. Deep Neural Networks in High Frequency Trading, https://arxiv.org/pdf/1809.01506.pdf. (Erişim Tarihi: 01/12/2019).

[12] Gudelek M.U., Boluk S.A., Ozbayoglu A.M. 2017. A deep learning based stock trading model with 2-D CNN trend detection. 2017 IEEE Symposium Series on Computational Intelligence (SSCI), Honolulu, HI, 1-8. doi: 10.1109/SSCI.2017.8285188.

[13] Karatas G., Demir O., Sahingoz O.K. 2018. Deep Learning in Intrusion Detection Systems. 2018 International Congress on Big Data, Deep Learning and Fighting Cyber Terrorism (IBIGDELFT), Ankara, Turkey, 113-116.

[14] Sahingoz O.K., Baykal S.I., Bulut D. 2018. Phishing Detection From URLs By Using Neural Networks. Computer Science \& Information Technology (CS \& IT), SPPR, SCAI, CSIA, WiMoA, ICCSEA, InWeS, NECO, GridCom - 2018, Sydney, Australia, 41-54.

[15] Kumar S., Ningombam D. 2018. Short-Term Forecasting of Stock Prices Using Long Short Term Memory. 2018 International Conference on Information Technology (ICIT), Bhubaneswar, India, 182-186. doi: 10.1109/ICIT.2018.00046.

[16] Shao X., Ma D., Liu Y., Yin Q. 2017. Short-term forecast of stock price of multi-branch LSTM based on K-means. 2017 4th International Conference on Systems and Informatics (ICSAI), Hangzhou, 1546-1551. doi: 10.1109/ICSAI.2017.8248530.

[17] Sismanoglu G., Onde M.A., Kocer F., Sahingoz O.K. 2019. Deep Learning Based Forecasting in Stock Market with Big Data Analytics. 2019 Scientific Meeting on Electrical-Electronics \& Biomedical Engineering and Computer Science (EBBT), Istanbul, Turkey, 1-4.

[18] Zhong G., Zhang K., Wei H., Zheng Y., Dong J. 2019. Marginal Deep Architecture: Stacking Feature Learning Modules to Build Deep Learning Models. in: IEEE Access, 7: 30220-30233. 